\title{
THE ADHESIVE MECHANISMS OF MONO- GENETIC TREMATODES: THE ATTACHMENT OF PLECTANOCOTYLE GURNARDI (V. BEN. \& HESSE) TO THE GILLS OF TRIGLA
}

\author{
By J. Llewellyn \\ Department of Zoology and Comparative Physiology, University of Birmingham
}

(Plate I and Text-figs. I and 2)

Little is known of the mechanisms whereby trematode parasites of fish gills attach themselves to their hosts. The adhesive apparatus consists of a posterior set of suckers or clamps supported by skeletal bars (sclerites) whose arrangement varies considerably in the different species. Yet though the pattern of these sclerites forms the main basis for the classification of the 200 or so species of the Diclidophoroidea into its six families, the only attempts to describe the mechanism of attachment of these parasites to their hosts appear to be those of Cerfontaine (I896), who described the attachment of Diclidophora denticulata to the gills of Gadus virens, and of Sproston (1945a) and Llewellyn (I956a), both of whom described the attachment of Kuhnia scombri to the gills of Scomber scombrus. In the present paper the mechanism by which Plectanocotyle gurnardi (v. Ben. \& Hesse) adheres to its hosts Trigla cuculus L., and $T$. lineata $\mathrm{Gmelin}$ will be described.

Material was collected at Plymouth during the summers of $1953-55$, and investigated by the techniques previously described (Llewellyn, I956a) for Kuhnia scombri. In addition, the tendon connecting each extrinsic muscle to its respective clamp was further characterized in histological sections by its positive response to the periodic acid-leucofuchsin routine for the demonstration of polysaccharides (Pearse, 1953), after treatment with ptyalin to remove glycogen from the muscles, and followed by treatment with picric acid to counterstain the muscles and sclerites.

\section{The AdHesive Mechanism}

The adhesive apparatus of Plectanocotyle consists of three pairs of clamps and a variable number of hooks, all borne ventrally in the posterior region of the body (Pl. I, fig. I). A pair of anteriorly placed suckers is also present, but these suckers are essentially a component of the feeding mechanism, and will be described elsewhere. The clamps and hooks are all applied to the secondary gill lamellae of one surface of a primary lamella in a manner I have described 
previously in a comparative account of the adhesive attitudes of gill trematodes (Llewellyn, I956 b).

The hooks are borne on a posterior appendage (Pl. I, fig. I) and function as anchors; such is their efficiency that after separating the clamps from the host tissue during the collection of specimens, it is often impossible to remove the parasite without rupturing the posterior appendage and leaving the hooks still engaged in the secondary gill lamellae. There are invariably two pairs of anchor hooks of which the hooks of the outer pair are about twice as long as those of the inner pair, and sometimes a third much smaller pair of hooks is also present. It is possible that this third pair of hooks may be surviving larval hooks, but an examination of fifteen specimens (histologically fixed and flattened) of Plectanocotyle gurnardi revealed no correlation between the size of the specimen and the presence of the third pair of hooks.

Each clamp consists of a postero-ventrally directed pair of hinged opposable jaws with the hinge axis lying approximately transversely across the body, so that one of the jaws lies anteriorly, and the other posteriorly. When the clamp grasps the secondary lamellae of the host, it is the distal end of the posterior jaw that is swung anteriorly about the proximal hinge axis, so that the posterior jaw may be conveniently referred to as the 'movable jaw' and the anterior one as the 'fixed jaw'.

The walls of the clamp consist mainly of fibrous tissue (Ft in Pl. I, fig. 4) supported by a framework of skeletal bars or sclerites $(a, b, c, d$ and $e$, in Pl. I, figs. I-8, and Text-fig. I). Of these sclerites, a single $\mathrm{J}$-shaped one (a) lies in the sagittal plane of the clamp. The curved region of the $J$ lies proximally in the clamp, with the short arm extending about half-way into the anterior jaw, and the longer arm extending about three-quarters of the way into the posterior jaw. Sclerite $a$ is $\mathrm{V}$ - or $\mathrm{Y}$-shaped in transverse section, with the groove facing away from the cavity of the clamp. It is the presence of this groove which gives sclerite $a$ the appearance of being hollow when seen in optical section as in Pl. I, fig. 6.

The terminal region of sclerite $a$ lying in the posterior jaw is elaborately fashioned to form an important part of the clamping mechanism: the lateral portions of the sclerite, i.e. the arms of the $Y$, are continued distally and expand to form a lamellate structure that in surface view is approximately semicircular in outline, with the diameter lying proximally and transversely in the posterior jaw of the clamp (Pl. I, figs. 6, 7). The basal region of the sclerite, i.e. the stem of the $Y$, continues its distal course for a short distance anteriorly to the lamellate expansion, i.e. it forms a short peg running beneath (=nearer to the cavity of the clamp) this lamellate expansion. The lamellate end of $a$ does not lie in one plane in the posterior jaw, but curves down over the short peg-like extension of the base of the grooved sclerite, i.e. it curves anteriorly in towards the cavity of the clamp, and then its distal margin is folded posteriorly through $180^{\circ}$ so that a transverse groove is formed. In its 
median region the posterior wall of this groove is greatly thickened, and opposite the centre of the thickened region the groove itself is perforated to permit the passage of a slender tendon (Pl. I, fig. 4) which connects the extrinsic muscles of the clamp with the hinged jaw. From the antero-distal surface of the thickened margin arises a pair of ridges running parallel to the median longitudinal axis of the clamp and which are continuations of the side walls of the perforation (Pl. I, fig. 2). They project towards the cavity of the clamp, and between them enclose a groove which serves as a guide for the tendon. The posterior distal end of sclerite $a$ thus constitutes a 'fair-lead' such as I have described (Llewellyn, I956a) in Kuhnia scombri.

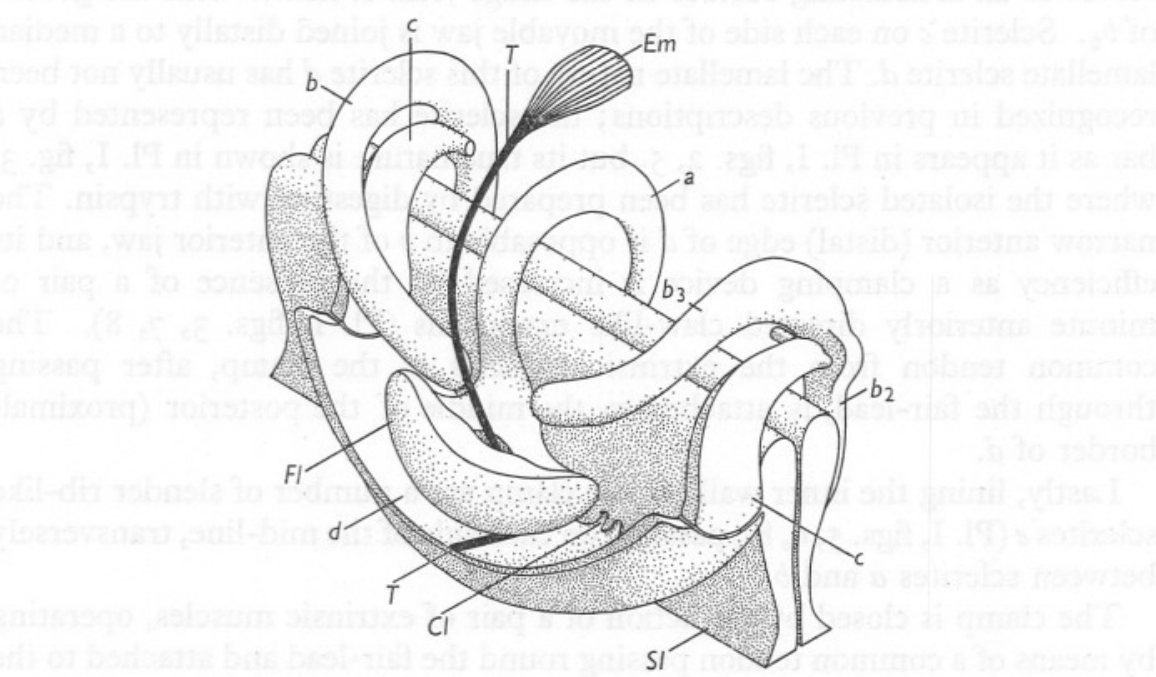

Text-fig. I. Stereogram of clamp of Plectanocotyle gurnardi grasping secondary gill lamellae of host. $a, b, b_{2}, b_{3}, c, d$, sclerites (see text, pp. 508-10); $\mathrm{Cl}$, claw; $\mathrm{Em}$, extrinsic muscle; $\mathrm{Fl}$, fair-lead; $S l$, secondary gill lamella; $T$, tendon.

Two systems of sclerites support the peripheral regions of the jaws of the clamp; one of these systems $(c, d)$ lies wholly within the posterior, movable jaw, while the other $(b)$ lies mainly in the anterior, fixed jaw, but extends also into the proximal region of the posterior jaw.

Sclerite $b$ passes, on each side of the clamp, along the margin of the anterior jaw $\left(b_{1}\right)$, then curves through the proximal, hinge region of the clamp $\left(b_{2}\right)$, and finally curves again, obliquely medianly into the proximal region of the posterior jaw $\left(b_{3}\right)$ towards its fellow from the opposite side. The distal ends of the two $b_{1}$ regions meet each other in the anterior jaw apparently without any actual fusion of sclerite material, while the distal ends of the $b_{3}$ regions in the posterior jaw are separated from each other by the median sclerite $a$. Sclerite $b$ consists of a flattened bar that in its anterior distal region $b_{1}$ presents 
its narrow edge towards the opposable margin of the posterior jaw; in its proximal region $b_{2}$ it bears an outwardly directed shelf-like projection which is grooved on its posterior surface to receive the articulating region of the movable jaw; and in its posterior distal region $b_{3}$, sclerite $b$ presents a narrow edge distally and a wider surface towards the cavity of the clamp.

The margins of the posterior jaw are supported by three sclerites. In the proximal region of each side is a sclerite $c$ consisting of a flattened tapering bar with its wider end lying distally, and with its narrower edges facing anteriorly and posteriorly. The proximal end of $c$ bears a peg-like extension directed laterally inwards towards the sagittal plane of the clamp, and which serves as an articulating surface in the hinge joint it makes with the groove of $b_{2}$. Sclerite $c$ on each side of the movable jaw is joined distally to a median lamellate sclerite $d$. The lamellate nature of this sclerite $d$ has usually not been recognized in previous descriptions; the sclerite has been represented by a bar as it appears in P1. I, figs. 2, 5, but its true nature is shown in P1. I, fig. 3, where the isolated sclerite has been prepared by digestion with trypsin. The narrow anterior (distal) edge of $d$ is opposable to $b$ of the anterior jaw, and its efficiency as a clamping device is increased by the presence of a pair of minute anteriorly directed claw-like extensions (Pl. I, figs. 3, 7, 8). The common tendon from the extrinsic muscles of the clamp, after passing through the fair-lead, is attached to the middle of the posterior (proximal) border of $d$.

Lastly, lining the inner walls of the clamp are a number of slender rib-like sclerites $e$ (Pl. I, figs. 5, 6, 8), passing, on each side of the mid-line, transversely between sclerites $a$ and $b$.

The clamp is closed by the action of a pair of extrinsic muscles, operating by means of a common tendon passing round the fair-lead and attached to the posterior margin of sclerite $d$. On contraction of the muscles, the movable jaw swings anteriorly about its hinge joint with $b_{2}$, and secondary gill lamellae are grasped between the opposable edges of $b$ and $d$. The course of the extrinsic muscles is illustrated in Text-fig. 2: each clamp is served by two muscles, one of which, the inter-clamp muscle, runs directly across the body to the fellow clamp on the other side, and the other, the longitudinal muscle, turns anteriorly in the body to join with the corresponding muscles from all the other clamps to form a broad longitudinal band of muscle running to the anterior end of the parasite. This pattern of musculature whereby paired clamps are connected to each other by a common inter-clamp muscle obviously increases the efficiency of both the clamps, since each clamp acts as a firm origin for the muscle inserted on the other clamp. It is questionable whether the primary function of the longitudinal muscles is to operate the clamps; they could do so efficiently only when they have a relatively firm origin, otherwise the effects of their contraction would be dissipated into shortening the body rather than bringing about the closing of the clamp. On the other 
hand, when the anterior end of the parasite is attached to the host during feeding, the efficiency of both the posterior clamping mechanism and the anterior feeding mechanism would be increased. Another possible function of the longitudinal clamp muscle could be the manoeuvring of the anterior end of the body.

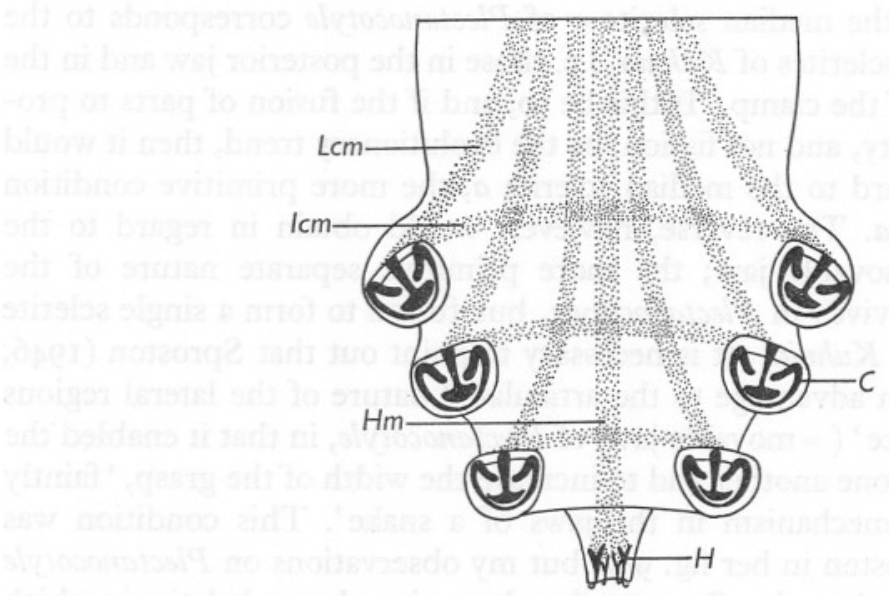

Text-fig. 2. The musculature of the adhesive organs of Plectanocotyle gurnardi. C, clamp; $\mathrm{H}$, hook; $\mathrm{Hm}$, hook muscle; Icm, inter-clamp muscle; $\mathrm{Lcm}$, longitudinal clamp muscle.

\section{Discussion}

Plectanocotyle gurnardi has been shown to have an adhesive mechanism similar to that of Kuhnia scombri. The main differences lie in the number of clamps, there being three pairs in Plectanocotyle and four pairs in Kuhnia, and in the relative sizes of the hooks in the two trematodes. The large hooks of Kuhnia are about twice as long as the proximal-distal axis of one of its clamps, but the large hooks of Plectanocotyle are only about half as long as the corresponding length of one of its clamps. Again, while the hooks of Kuhnia are borne on the ventral surface of the body proper, those of Plectanocotyle are borne on what appears to be a slender posterior appendage, but an assessment of the significance of this is probably best left until the larval development of these parasites has been studied.

Though the clamping mechanisms in Plectanocotyle and Kuhnia are so similar to each other, there are differences in the detailed arrangement of the supporting sclerites that are of considerable phylogenetic interest. The support given to the median region of the clamp of Plectanocotyle by the single sclerite $a$ is provided in Kuhnia by three quite distinct lamellate sclerites, the two in the anterior and posterior jaws lining the fibrous walls of the clamp, and the one in the proximal region of the clamp lying outside the fibrous wall, i.e. lying between the clamp wall and the remainder of the body. It is probable 
that a detailed investigation of the development of sclerites and their relationship with other tissues would contribute much to the establishment of the precise homologies of diclidophoroidean sclerites, but here it is suggested tentatively that the rib-like sclerites $e$ lining the wall of the clamp of Plectanocotyle are represented by the single lamellate sclerite lining the anterior jaw of Kuhnia, and that the median sclerite $a$ of Plectanocotyle corresponds to the other two median sclerites of Kuhnia, i.e. those in the posterior jaw and in the proximal region of the clamp. If this be so, and if the fusion of parts to promote greater rigidity, and not fission, be the evolutionary trend, then it would follow that in regard to the median sclerite $a$, the more primitive condition survives in Kuhnia. The reverse, however, would obtain in regard to the sclerites of the movable jaw; the more primitive separate nature of the sclerites $c, d, c$ survives in Plectanocotyle, but fusion to form a single sclerite has taken place in Kuhnia. It is necessary to point out that Sproston (I946, p. 4I4) ascribed an advantage to the articulated nature of the lateral regions of the 'middle piece' (= movable jaw) of Plectanocotyle, in that it enabled the parts to slide over one another and to increase the width of the grasp, 'faintly analogous to the mechanism in the jaws of a snake'. This condition was illustrated by Sproston in her fig. $95 f$, but my observations on Plectanocotyle have convinced me that what Sproston has drawn is a clamp skeleton in which the jaws have been forced open and the sclerites disarticulated, possibly by pressure of the cover glass during microscopy.

It is unnecessary to repeat here the criticisms I have made previously (Llewellyn, I956a) of Sproston's (1945b) general theory of the evolution of clamping mechanisms in the Diclidophoroidea; it is sufficient to state that in Plectanocotyle I have been quite unable to reconcile for example Sproston's description of the 'middle piece' (= movable jaw sclerites) having its 'anterior' (=proximal) border cuticularized and joined with the 'median spring' (=sclerite $a$ ) by a median cuticularized band, with anything that I have observed in Plectanocotyle. As for Sproston's observation that the clamp structure of the Plectanocotylinae is discocotylid in general pattern, it appears to me to be much more like Kuhnia scombri than Discocotyle sagittata. Furthermore, a preliminary examination of the adhesive mechanisms of the thirteen species of Plymouth diclidophoroideans that I have studied for other purposes (Llewellyn, I956b), indicates that Plectanocotyle gurnardi, Kuhnia scombri and Mazocraes alosae all have very similar mechanisms involving a fair-lead, and all differ substantially from the remainder of these trematodes. If, then, clamp structure is of major phylogenetic significance, Kuhnia, Mazocraes and Plectanocotyle are closely related to each other. Acceptance of this idea would, however, present a new problem: in general, among the Polyopisthocotylea, groups of nearly related parasites are restricted in their distribution to groups of nearly related hosts, e.g. the Diclidophorinae on the Gadidae, and the Cyclocotylinae (= 'Choricotylinae') on the Sparidae; but 
the three closely related (?) genera Mazocraes, Kuhnia, and Plectanocotyle would then form a group parasitizing such widely divergent host families (Berg, 1947) as the Clupeidae (Clupeiformes), Scombridae (Perciformes, Scombroidei), and Triglidae (Perciformes, Cottoidei).

It is a pleasure to record my thanks to the Director and Staff of the Plymouth Laboratory for collecting facilities, and to Miss Barbara Williams for technical assistance.

\section{SUMMARY}

The mechanism by which the monogenetic trematode Plectanocotyle gurnardi attaches itself to the gills of various species of Trigla has been shown to consist of hooks borne on a posterior appendage, together with three pairs of clamps which, although differing somewhat in structure, act by an extrinsic muscletendon-fair-lead-hinged jaw mechanism in exactly the same manner as Kuhnia scombri on Scomber scombrus. On the basis of clamp structure, Plectanocotyle appears to be more nearly related to the Mazocraeidae than to the Discocotylidae in which it is included at present.

\section{REFERENCES}

BeRG, L. S., 1947. Classification of Fishes, both Recent and Fossil. Ann Arbor, Michigan: J. W. Edwards.

Cerfontaine, P., I896. Contribution à l'étude des Octocotylides. I-III. Arch. Biol., Paris, T. I4, pp. 497-560.

Llewellyn, J., I956a. The mechanism of the attachment of Kuhnia scombri (Kuhn, I829) (Trematoda: Monogenea) to the gills of its host Scomber scombrus L., including a note on the taxonomy of the parasite. Parasitology (in the Press).

- I956 b. The host-specificity, micro-ecology, adhesive attitudes, and comparative morphology of some trematode gill parasites. F. mar. biol. Ass. U.K., Vol. 35, pp. II $3-27$.

Pearse, A. G. E., I953. Histochemistry. London: J. and A. Churchill.

Sproston, N. G., I945a. The genus Kuhnia n.g. (Trematoda: Monogenea). An examination of the value of some specific characters, including factors of relative growth. Parasitology, Vol. 36, pp. I76-90.

- $1945 b$. A note on the comparative anatomy of the clamps in the superfamily Diclidophoroidea (Trematoda: Monogenea). Parasitology, Vol. 36, pp. I9I-4.

- 1946. A synopsis of the monogenetic trematodes. Trans. zool. Soc. Lond., Vol.25, pp. $185-600$. 


\section{EXPLANATION OF PLATE I}

The adhesive mechanism of Plectanocotyle gurnardi

Fig. I. Posterior end of the parasite in ventral view, showing the three pairs of clamps and two pairs of hooks. Due to the flattening of the specimen beneath a cover-glass, the clamps are seen in anterior view.

Fig. 2. The pair of ridges on the anterior surface of the fair-lead which act as a guide for the tendon. ( $\times 40$ phase contrast objective used with $\times 95$ substage annulus.)

Fig. 3. The distal median sclerite (' $d$ ') of the posterior movable jaw, isolated by digestion of the other tissues with trypsin.

Fig. 4. Sagittal section of distal region of clamp, showing the tendon passing around the fair-lead to the movable jaw.

Fig. 5. Clamp in anterior view. (Stained preparation in Canada Balsam.)

Fig. 6. Clamp in posterior view. (Same clamp as in Fig. 5.)

Fig. 7. Sclerites of a whole clamp remaining after other tissues have been digested with trypsin. The sclerites of the posterior jaw have become disarticulated. Posterior view.

Fig. 8. Another clamp from the same specimen as in Fig. 7, similarly treated. Side view.

\section{Abbreviations}

$a, b, b_{1}, b_{2}, b_{3}, c, d, e$, sclerites (see text, pp. 508-10); $C l$, claw; $F t$, fibrous tissue; $F l$, fair-lead; $T$, tendon. 

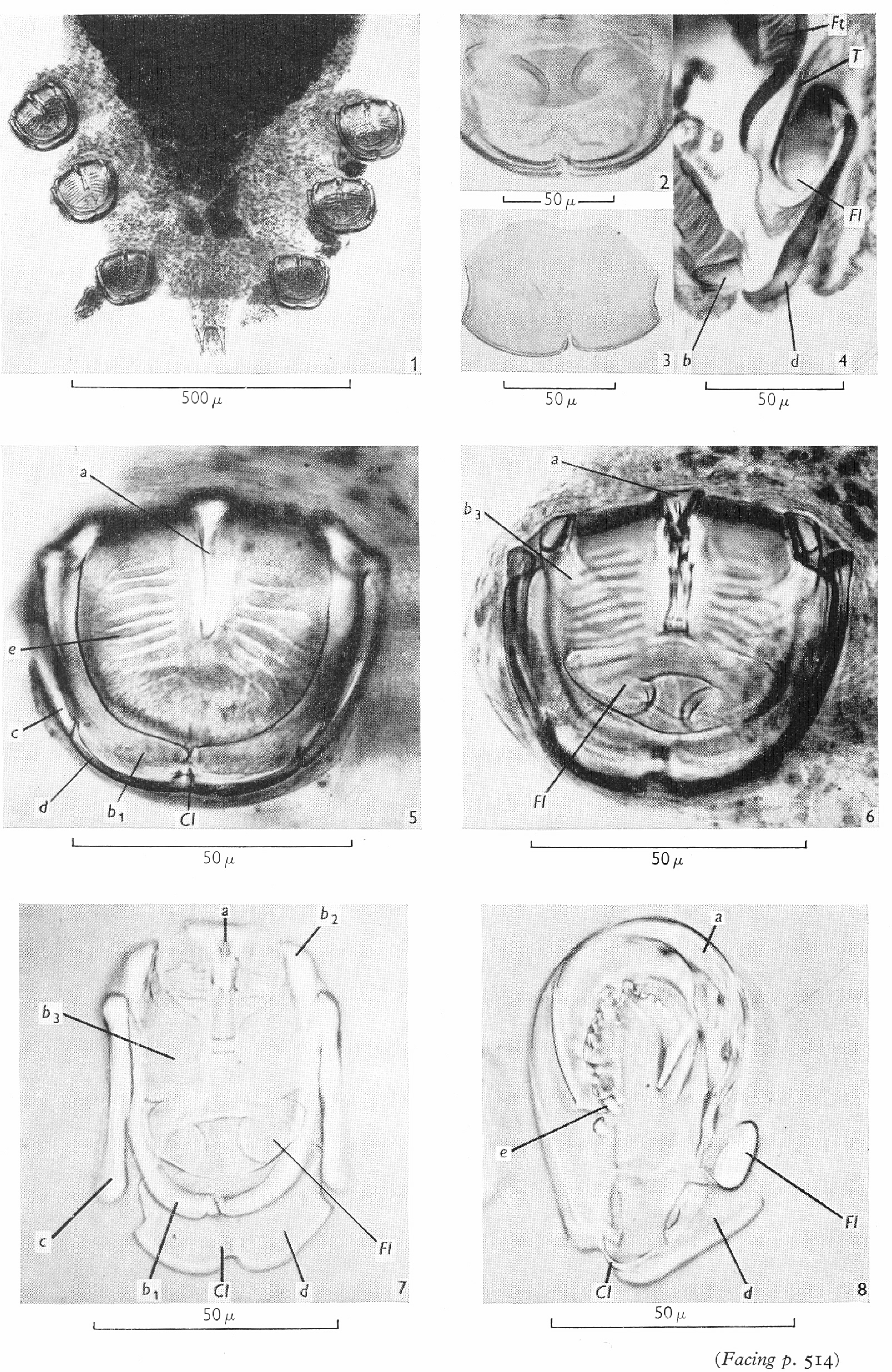